\title{
Towards Inclusive, Quality ICT-Based Learning for Rural Transformation
}

\author{
Vinayagum Chinapah* and Jared O. Odero \\ Institute of International Education, Stockholm University, Sweden
}

\begin{abstract}
Information and communication technology (ICT) has emerged as a tool that can enhance flexible learning pathways. ICT has the potential to increase equitable access to quality learning, which is essential for skills development. Skills are required in technology-related nonfarm activities so as to improve livelihoods and achieve sustainable rural transformation. However, slow pace of the developing countries to utilize the benefits of the ongoing technological revolution in the North has resulted in the 'digital divide'. Besides, it is still problematic to implement ICT programmes for educational development. The current and future challenges of providing ICT-based learning desperately call for the reengineering of education to move out of the formal structure of teaching and learning, towards building a more practical and realistic approach. By means of a literature review, this paper examines and discusses why it is important to provide inclusive, quality ICT-based learning, particularly in the rural areas of Asia and sub-Saharan Africa (SSA). It recommends that diverse ICT-based solutions be adopted to promote skills development and training within non-formal and informal settings. More comparative studies are also required to understand the impact of ICT-based learning in rural areas.
\end{abstract}

Keywords: Inclusive quality ICT-based learning, rural transformation, Asia, sub-Saharan Africa 


\section{Introduction}

Information and communications technology (ICT) has emerged as a tool that can boost flexible learning pathways through non-formal and informal education. Further, it has the potential to increase equitable access to quality learning, which is essential for skills development. Consequently, ICT skills are important in advancing technology-related nonfarm activities that can improve livelihoods and help to achieve sustainable rural transformation (Haijun, Weifeng, Jinghua, \& Rong, 2015; Li, Ahmed, Khan, \& Hongwei, 2016; Mamba \& Isabirye, 2015; Pade-Khene, Mallinson, \& Sewry, 2011).

Access to ICT has improved worldwide and mobile phones in particular have become ubiquitous and currently facilitate mobile banking, learning, social media participation, software applications and employment. However, slow pace of the developing countries to utilize the benefits of the ongoing technological revolution in the North has resulted in the 'digital divide'. Findings from a study by the McKinsey Global Institute published in 2014 on barriers to the Internet showed that out of the estimated 4.4 billion people worldwide who were offline or unconnected to the Internet, $75 \%$ lived in 20 developing and developed countries; $64 \%$ lived in rural communities; $28 \%$ were illiterate; $50 \%$ had earnings below the average poverty line of their country; $18 \%$ were aged 55 or older; and $52 \%$ were women (Enriquez et al., 2014).

The World Development Report 2016 revealed that despite the ubiquity of digital devices and the increasing role of digital technologies in every aspect of human life, "digital dividends - the broader development benefits from using these technologies - have lagged behind. In many instances digital technologies have boosted growth, expanded opportunities, and improved service delivery. Yet their aggregate impact has fallen short and is unevenly distributed" (World Bank, 2016, p. 2). Two factors that contribute to barriers in the enjoyment of digital dividends are: (1) the huge numbers of people (60 percent) who do not have access to the Internet and cannot therefore participate in the digital economy. In addition, some half a billion people live in remote areas without a mobile signal. (2) Labor market preferences in the developed countries that tend to favour persons with advanced skills who replace those with lower skills. Without accountable institutions, public investments in digital economies will continue to "amplify the voices of the elites, which can result in policy capture and greater state control. Not surprisingly, the better educated, well connected, and more capable have received most of the benefits - circumscribing the gains from the digital revolution" (p. 3). 
Over and above the digital divide, many developing countries still face the challenge of implementing ICT programmes to facilitate educational development at the local, national and regional levels, because of the inadequate number of skilled personnel, poor ICT infrastructure especially in the rural areas, insufficient funding of programmes for sustainable development, and inadequate strategies for integrating ICT policies into their education systems.

The current and future challenges faced in providing ICT-based learning desperately call for the reengineering of education, to move out of the formal structure of teaching and learning towards building a more practical and realistic approach. By means of a literature review, this paper examines and discusses why it is important to provide inclusive, quality ICT-based learning, chiefly in the rural areas of Asia and sub-Saharan Africa (SSA). The paper recommends that more ICT-based solutions be adopted to promote skills development and training, specifically within non-formal and informal settings, for rural inhabitants. More comparative studies are required to understand the impact of ICT-based learning in rural areas.

\section{The State of Rural People}

Rural areas, specifically in Asia and SSA, are characterized by their cultural, social and economic diversity. They consist of sparse human populations whose key occupations are farming, pastoralism and fishing. Conversely, a rural nonfarm economy exists and chiefly alternates with the agricultural season, and includes various activities such as self-employment, trading, manufacturing, and agroprocessing. It also consists of Internet and phone services, health clinics and milling business. The nonfarm economy is a crucial source of employment for rural women in most regions, considering the limited opportunities they have due to gender bias in the formal employment sector, and other cultural barriers to property ownership (International Fund for Agricultural Development, 2010).

Rural communities are generally occupied by extremely poor populations that are marginalized socioeconomically. Poverty has many dimensions besides being a state of existence, and comprises lack of material ownership, lesser ability to survive, and helplessness (Khan, 2000). The global Multidimensional Poverty Index (MPI) 2014 that is derived from three equally-weighted dimensions (e.g. health, education and standard of living measured by ten indicators), showed that $85 \%$ of the multidimensionally poor people across 105 countries, lived in rural communities and the regions of SSA and South Asia accounted for $86 \%$ of the share (Alkire, Chatterjee, Conconi, Seth, \& Vaz, 2014). 
Poverty is a combination of political and socioeconomic circumstances, and requires multiple interventions to be eradicated. Poor people are not only deprived of possessions or information, they are also marginalized, discriminated, excluded, and are facingsocial inequalities (Clarke, Wylie, \& Zomer, 2013). Most rural people are marginalized and suffer a severe and tenacious disadvantage, deeplyrooted in social inequalities. Marginalization is an outcome of institutionalized disadvantage perpetuated by policies and processes. It is characterized by informal discrimination, which is entrenched in socio-political and economic processes that hinder certain groups and individuals, from participating in opportunities to improve their quality of life (United Nations Educational, Scientific and Cultural Organization [UNESCO], 2010).

Around 836 million people worldwide live in extreme poverty, compared to 1.9 billion in 1990 . Additionally, three-quarters of the extremely poor people still live in rural areas, and account for $46 \%$ of the world's population (United Nations [UN], 2014). They continue to be vulnerable to poverty, malnutrition and poor health, gender inequality, lack of education, ecological disasters, and food insecurity. The figures that depict the current status of the world's poor reveal an unacceptable reality.

The International Labor Organization 2015 report on Global Evidence on Inequities in Rural Health Protection revealed that rural populations worldwide, especially those in developing countries, suffer immense access gaps in basic healthcare services compared to those in urban areas. Nearly $83 \%$ of the people in Africa are not legally covered, principally in the poorest countries (Scheil-Adlung, 2015). Furthermore, a report published by the Food and Agriculture Organization (FAO) in 2015 on the state of food insecurity maintains that populations without alternative sources of income or employment are largely situated in the rural villages of Africa and Asia, which are also home to three-quarters of the world's hungry people (FAO, 2015).

Some $98 \%$ of the people killed or those who get affected by natural disasters are from developing countries, and by 2025 , more than half of them may be vulnerable to floods and storms. At the same time, water scarcity is expected to affect more than 1.8 billion people - hurting agricultural workers and poor farmers the most (Olinto, Beegle, Sobrado, \& Uematsu, 2013; UNESCO, 2015a).

\section{Importance of ERT}

Education is a precondition for rural transformation since it empowers 
marginalized people to make better choices and to take control of their lives. Above and beyond, it is known that educated people have the possibility of earning a higher income and are comparatively not marginalized in the wider society (Sharma, 2014). Marginalized people are deprived of full access to education. For illustration, poorer females aged 15 to 30 have a year less of school attendance than males of the same age, signifying the overwhelming global gender gap in education amidst the poor (Olinto et al., 2013). The UNESCO Institute for Statistics (2015) notes that out of the 59 million children (55\% girls) and 65 million adolescents (52\% girls) who were out of school globally in 2013, 30 million lived in SSA and 10 million in South and West Asia. Furthermore, from the estimated 781 million adults and 126 million youths who lacked basic reading and writing skills in 2012, more than $60 \%$ were women. Moreover, rural primary school-aged children are twice as likely to be out of school compared to their urban counterparts (UN, 2014). On a positive note, the Millennium Development Goals [MDGs] Report 2015 indicated an outstanding growth in primary school enrolment rates in many countries and regions. In SSA, enrolment rose from 52\% in 1990 to $78 \%$ in 2012, while in Southern Asia, it increased from $21 \%$ to $42 \%$, despite political strife, increasing population and poverty (UN, 2015).

Any type of education has the potential to provide change and development for rural people. It is therefore important to promote education not only as a tool for poverty alleviation, but also as a fundamental part of human development and wellbeing. Education for rural transformation requires a paradigm shift to move away from the traditional and formal modes of education (a schooling perspective), to new forms of teaching and learning (a learning perspective). For instance, non-formal learning and training can be alternatives for people who have not undertaken formal education (Rabinowicz \& Chinapah, 2014).

The concept of rural transformation expresses a dynamic vision of change and positive growth among rural inhabitants, in relation to national and global changes. While education is fundamental in guiding the achievement of rural transformation, it should be noted that the transformative outlook of rural change does not renounce the basic approach to rural development. On the contrary, rural transformation argues for a more diversified view of development that is inclusive of women and the youth, multifaceted and transformative, for both national and rural development (Ahmed, 2014; Li et al., 2016).

The rural transformation agenda in SSA is all-inclusive and aims to improve the quality of life in rural communities. It involves supporting investments in 
health, education, and rural infrastructure; creating reliable financial markets; formulating policies that can enhance more gender parity and the empowerment of rural people. Such policies are important for the most susceptible who require effective safety-net programmes. Small-scale rural farmers also need support to join innovative markets and to boost their roles in the whole value chain (Boto, Fotabong, Proctor, Lopes, \& Kebe, 2011).

Rural transformation outcomes vary in SSA, yet they are connected with the broader structural, economic and social transformation processes occurring globally, regionally, within countries, local societies and institutional frameworks. No growth can be realized without investing both in economic fundamentals (macroeconomics, good governance, openness, etc.) and structural transformation (infrastructure, technology, rural transformation, etc.). Investing in the rural economy reduces the risk of increased poverty (Shimiles, 2015).

The report, Education for Rural Transformation: Towards a Policy Framework, by the UNESCO International Research and Training Center for Rural Education (INRULED), was written with the purpose of commencing debate and establishing a framework for policy and action that would put education at the forefront of rural transformation. The report discussed the importance of re-focusing education to consider the needs of rural people in developing countries in order to attain rural transformation. It also noted that educational policies, plans and programmes basically disregarded rural communities, whereas national and global initiatives had not improved the historical rural-urban educational inequalities. Moreover, pertinent valuable data and information about rural contexts and urban-rural disparities were almost nonexistent in many aspects, including education. The report asserted that though ICT was perceived as a potential tool for enhancing access to educational programmes, content and quality of learning, pro-active policy and commitment were necessary so as to bring ICT to rural populations (UNESCO-INRULED, 2001).

The 2012 report on Education and Training for Rural Transformation: Skills, Jobs, Food and Green Future to Combat Poverty published by UNESCOINRULED, underscored the need for diverse learning pathways (non-formal and informal), so as to raise the skills of rural people and make them productive to fight poverty. Citing successful rural poverty reduction projects funded by the Asian Development Bank in Vietnam, China and Malaysia, the report argued that the approach required a longer-term and broader intervention connected to a regional framework. These countries have also made significant improvement 
in macroeconomic growth. Since nonfarm economic activities account for around half of the rural income in developing countries, they create employment pathways out of poverty.

Evidence suggests that nonfarm income contributes to growth and poverty reduction. For instance, mobile phones have revolutionized banking services by facilitating mobile cash transfers and other commercially-related services at affordable fees. In parts of Asia and Africa, many women are currently employed as mobile money franchise operators or agents in mobile finance services, and use the income to improve their own quality of life and that of their children's. In rural Kenya, mobile banking has empowered a number of women through savings and microfinancing activities. As a consequence, they are less dependent on their spouses for money to manage household purchases (Global System for Mobile Association's mWomen, 2013).

However, the 2012 UNESCO-INRULED report equally recognized the existence of varied challenges in generating skills and jobs through education and training due to gaps in policy and practice. In SSA and South Asia, many factors such as financial constraints faced by governments, farm activities, and local traditions, result in low school participation and achievement for many children. These reasons also hinder most rural people from succeeding within higher education (UNESCO-INRULED, 2012). Likewise, the opportunities for non-formal and informal skills development, adult and lifelong learning, are still inadequate in many developing countries (Ahmed, 2014).

\section{Inclusive, Quality ICT-based Learning}

This section first describes what entails inclusion and quality in education. It then reflects on some good practices and challenges faced in providing ICTbased learning in rural communities. Though the concept of inclusive education is very broad, it is defined by UNESCO (2005) as "an approach that looks into how to transform education systems and other learning environments in order to respond to the diversity of learners" (p. 15). Inclusive learning practices allow individuals to learn at their own pace according to their emotional, cognitive and creative capacities. Moreover, according to UNESCO (2005), inclusion is emphasized in the three principles that recognize education as a basic human right, namely, "access to free and compulsory education; equality, inclusion and non-discrimination; the right to quality education, content and processes" (p. 12).

Good quality education is recognized as a basic human right and the 
World Declaration on Education For All (EFA) in 1990 underscored that education should be provided to all children, youth and adults according to their needs, relevance and expectations in life. The concept of quality education is also a central component in the Incheon Declaration that was adopted by the international community during the World Education Forum 2015. The Declaration advocates that in order to transform lives through education, it is imperative to provide equitable and inclusive education and lifelong learning for all by 2030 (UNESCO, 2015b).

Good quality education should be provided by trained teachers. Nonetheless, most developing countries suffer from a huge shortage of qualified teachers. In addition, many teachers are poorly paid leading to demotivation that affects the quality of teaching and learning. Quality learning is important in facilitating global peace, communal interrelations and sustainable development. Approaches that promote active, collaborative and self-directed learning for the youth are vital for their success and community participation. Achieving good quality education requires mentors, teachers, appropriate curriculum and learning resources that can equip the youth with pertinent skills for the 21 st century employment opportunities (UNESCO, 2015b).

\section{ICT in Education}

The process of integrating ICT into education systems has been a central subject of research in educational reform during the last two decades, and has included the broad goals of applying ICT for equity of access to education, and for the improvement in learning quality. Global normative goals have also dominated the discourse on ICT in education. For instance, the 2000 Dakar Framework for Action recommended harnessing ICT at an affordable cost in EFA. This would be done through dissemination of knowledge, effective learning and by providing more efficient education services (Khan, Hasan, \& Clement, 2012).

Target $8 \mathrm{~F}$ within Goal 8 of the MDGs stated that the benefits of ICT should be made available through cooperation with the private sector. However, Clarke et al. (2013) aver that the MDGs did not give prominence to ICT, yet they were launched during the emergence of the 'knowledge economy' concept. Kenny and Dykstra (2013) have equally questioned the role of international cooperation in the ubiquitous ICT rollout and mobile phone ownership, claiming they have instead been enabled by technological and economic factors.

In September 2015, the international community adopted the Post-2015 
Development Agenda, which succeeded the MDGs and includes 17 Sustainable Development Goals (SDGs) that aim to eradicate poverty, combat inequality and injustice, and deal with climate change by 2030. Similarly, to affirm a joint global commitment to release the full potential of ICT for education to accomplish the SDGs, the international community adopted the Qingdao Declaration in Qingdao City, China, in May 2015. ICT has now been given a more central role in the new Education 2030 Framework for Action, whose key pillars are access, equity and inclusion, quality and learning outcomes for all, within a lifelong perspective. Nevertheless, Ahmed (2014) is concerned that rural communities have not been given a prominent position in the SDGs framework.

Although a lot has been done worldwide to increase participation in education, the discourse on ICT for inclusive learning is still based upon the number of devices provided in the public education systems, instead of how they contribute to innovative learning. A study by Madden (2014) found that inclusive teaching practices allow students to learn in varied ways and at different rates. Equally, mobile technologies offer personalized learning models that can be inclusive to the excluded rural learners. However, Madden suggests that a paradigm shift is required to integrate mobile devices effectively into new learning environments that promote a student-centered approach, collaborative learning and constructivist pedagogy.

Whereas different inclusive approaches can be used in rural areas to enhance ICT-based learning, it is important to understand existing barriers. For instance, technological gaps include unequal access to interactive digital devices such as smartphones (mobile divide) due to the high cost of handsets and broadband connectivity; insufficient ICT literacy skills among many teachers and learners; and language usage on the Internet, which is largely English, that many rural people may not be able to understand. Likewise, in some societies, cultural barriers prevent women from accessing public spaces for Internet access and owning mobile phones.

\section{ICT Framework}

Rural communities are at the experimental level with ICT and a lot of scaling up is required to improve their livelihoods and educational development. It is therefore necessary to initiate a framework for informal and flexible opportunities beyond existing centralized and formal structures, to promote ICT literacy and other small scale strategic interventions among the women, youth and unemployed adults, who are locked out of formal education systems. As they enter 
adulthood, many youths will add to the growing number of illiterates who are unemployable and unproductive to the economy.

It is suggested that through public-private partnerships, learning centers can be built and equipped with appropriate technologies, to facilitate knowledge and information sharing, skills development and capacity building, through web-based courses and training. The ultimate goal is to enable members of these communities to benefit socioeconomically from ICT, in order to reduce poverty. Furthermore, sound policies and strong institutions are required to improve ICT access and use, through policy planning (Chapman \& Slaymaker, 2002; UNESCO-INRULED, 2012).

Technology alone does not alleviate rural poverty. Therefore, many other local and national factors which hamper development should be taken into account while designing a pro-poor ICT policy. Governments should develop accessible and effective ICT infrastructure for all by reforming the telecommunications sector and other related institutions, so as to deliver ICT services to rural areas. ICT policies that endorse broader flows of information and communication in developing countries can increase the potential for income generation and close the subsequent knowledge gap, which perpetuates poverty (Harris, 2004).

Figure 1 illustrates an ICT for Poverty Alleviation Framework by Harris (2004). The following five principles summarize the objectives of the framework:

Strategize for poverty alleviation, not for ICT; reform telecommunications through privatization, competition and independent regulation; promote public access: aggregate demand for sustainability (which is not only financial);

Reform institutions to achieve transformational benefits; develop appropriate approaches for listening to the poor. (p. 50)

The framework for poverty alleviation is provided as a tool to guide a multidimensional approach to development through ICT and cuts across various sectors. Harris suggests that ICT challenges traditional methods of development and assures

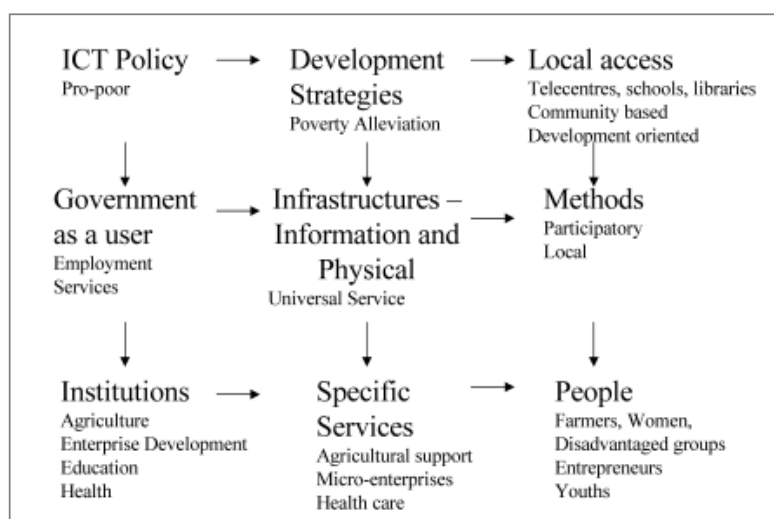

Figure 1. From policies to people: A framework for poverty alleviation with ICTs (Harris, 2004, p. 48). 
progress for the livelihoods of many poor people. The framework permits a complete consideration of pertinent aspects before beginning the implementation of a development project, and correspondingly, later reflections on results.

\section{Learning Communities}

Learning as a social process that fits into the context of rural areas can be more enriching when learners meet at community centers or telecenters and interact with professionals on the Internet to discuss local needs using their mother-tongue. This promotes interpersonal and intercultural contacts that are both formal and informal. The process of socialization improves the worldview of rural people and enables them to grasp what is happening beyond their local environment. Rural women can also develop social media networks with mentors that guide them to actively participate in local projects as part of lifelong learning. Such interactions can build up their confidence, creativity and leadership qualities. Interacting with women in similar situations motivates them to learn informally, increases their ICT skills, and encourages interdependency and emotional support (Pokorska, 2012).

\section{Skilled Teachers}

Schmitt (2015) contends that while mobile technology is revolutionizing banking and farming in most African countries, it is widening the divide between urban and rural communities in terms of access to education. Over the years, huge sums of money have been invested in ICT in education, yet many rural parts of SSA have not been reached. The author cites the experience of a primary school teacher in rural Tanzania whose pupils had rare access to the Internet, and when available, they mainly used it to communicate with family and friends. The teacher mentioned that it was meaningless to supply thousands of laptops in rural schools when most pupils could not even read and write.

For Schmitt (2015), only empowered teachers can help to realize the idealistic dream of using self-directed mobile learning so as to close the technology and gender gaps in education. An empowered teacher will not be threatened by technology and will spend time encouraging girls to attend school. Nevertheless, most teachers in rural SSA schools are poorly paid and cannot afford mobile devices that are increasingly being used for learning.

According to the UNESCO Working Paper Series on Mobile Learning for Teachers in Africa and the Middle East, various ICT-assisted initiatives including the provision of laptops, PC labs and the advent of open educational resources 
(OER) have been carried across Africa for teacher professional development. However, ICT access and the prospects for open and distance learning (ODL) are still restricted for teachers. Whereas mobile technologies, especially mobile phones, are emerging as a new area of support for pre-service and in-service teacher training through ODL programmes, there is a dearth of research-based evidence showing that mobile phones can improve and support the professional development of teachers and ODL in the region (Isaacs, 2012).

\section{Non-Formal Education}

Non-formal education (NFE) is an alternative type of education for adults and children that occurs outside of the traditional classroom environment. Due to its flexibility, NFE is suitable for the assorted and particular learning needs of children, youth and adults globally (Coombs \& Ahmed, 1974; Yasunaga, 2014). In the recent past, NFE has been viewed within the framework of providing EFA and the MDGs, in order to promote literacy and numeracy skills. For many years, ICT-based NFE initiatives have been used to promote mass literacy campaigns, training of health workers, and capacity building within rural community development projects. NFE projects are gradually shifting from the reliance on community radio, print media and television, to using new technologies to empower the voiceless through individual lifelong learning initiatives. Examples of ICT in NFE include Open Educational Resources (OERs) and Massive Open Online Courses (MOOCs).

A study by infoDev entitled ICT in Non Formal Education, has suggested that for ICT-assisted NFE programmes to succeed, they should have an all-inclusive policy formulation; community involvement; share best practices between communities and countries; produce localized content; and continually upgrade technology. Besides, to ensure sustainability, other stakeholders are urged to support governments during the implementation of NFE projects (infoDev, 2010).

The Asia-Pacific Program of Education for ALL (APPEAL) launched in 1987 by UNESCO, is an initiative that focuses on non-formal adult education. It supports the Asia-Pacific countries to organize NFE by training their educational employees and developing learning materials. Since 1998, APPEAL has been promoting the concept of Community Learning Centers (CLCs) to create grassroots-based interests and participation in literacy, basic education, and continuing education activities for the disadvantaged people. Since 2002, UNESCO has achieved the following: (1) sustained the use of ICT to provide education to out-of-school youth and adults; (2) developed and implemented 
country-level action plans; (3) strengthened the capacity of non-formal education practitioners; (4) supported and improved community learning centers; (5) established community tele-centers; (6) empowered rural communities by facilitating ICT skills; (7) organized workshops to share practices in the use of ICT in community learning and multi-media centers; and (8) developed a regional ICT support pack for non-formal education. APPEAL also stresses gender mainstreaming in all of its programmes (UN Economic and Social Commission for Asia and the Pacific, 2010).

\section{ICT Policy}

Public spaces for Internet access such as libraries, cybercafés and telecenters are very important for marginalized populations. Thus, they not only need a lot of investment to operate, they should also be affordable to the users in order to overcome digital inclusion. In China, the national and provincial governments are implementing a policy goal of providing ICT in the countryside, which is also referred to as 'rural informatization'. In their report, Information and Communications in the Chinese Countryside, A Study of Three Provinces, Minges, Kimura, Beschorner, Davies, and Zhang (2014) found that significant progress had been made to improve ICT infrastructure in China's rural areas, which consisted of more than 650 million people. All the villages in the study were connected to electricity and had a mobile telephone signal. By the end of 2012, there were 156 million rural Internet users, and broadband connectivity had reached $88 \%$ of the administrative villages. Even so, approximately only three-fifth of the urban Chinese accessed and used the Internet, while less than a quarter of the rural population did so. A central feature in the Chinese study is the established national network of public libraries that runs from the metropolitan centers to the villages, and is expected to bridge the digital gap by providing digital literacy and ICT skills development.

Though there are financial, administrative and maintenance challenges that limit the effectiveness of the libraries, Minges et al. (2014) noted that the rural ones are more utilized than the urban ones. In order to sustain the Chinese rural informatization programme, the report has recommended that telecommunications operators be focused more on operations than on infrastructure deployment. Moreover, public-private partnerships ought to be used for content and applications, to make the expertise of Chinese Internet companies more operational. Moreover, public Internet facilities should include income-earning services so as to share costs and enhance the demand for services. 
120 V. Chinapah\&J. O. Odero

\section{Mobile Internet Solutions}

Using Internet-connected buses, vans and three-wheeled motorcycles to reach learners in far-flung remote communities of Asia and SSA, is an interesting means of bringing digital teaching and learning resources to students. Such facilities are sometimes the only means of learning through a few monthly visits. However, the impact of such initiatives is not well-documented (Trucano, 2016). Compared to One Laptop Per Child (OLPC) initiative criticized by some people for being driven by politics and rhetoric, can mobile Internet solutions bring the desperately needed inclusion and good quality in education?

\section{Conclusion}

This article has examined the importance of ICT for learning in the rural areas across developing countries, specifically in Asia and SSA. It has also reflected on some good practices and challenges in implementing ICT-based learning. It found that mobile technologies, especially mobile phones, have become ubiquitous and can facilitate teaching and learning. Furthermore, effective policy frameworks and relevant reforms in the telecommunications sector have increased public-private partnerships that have expanded ICT services in rural areas. For instance, there is evidence that technology-related nonfarm activities such as mobile banking and other services have enabled women in the rural areas of Asia and SSA to make some income as mobile banking agents. The earnings help them to provide a better quality of life for their children, and also make them less dependent financially on their spouses. Equally, ICT enables rural inhabitants to participate in non-formal and informal learning to acquire skills.

Despite the rosy picture above, most rural people are not able to access the Internet because broadband connectivity is still very expensive and in some communities, cultural barriers and negative male attitudes hinder women from using public facilities connected to the Internet, or even owning mobile phones. Technological infrastructure should be expanded to include rural areas that are normally neglected due to the high cost of rolling out broadband connectivity and electricity supply. ICT skills are still restrictive even among many rural teachers in Asia and SSA who are also poorly paid and cannot afford to own smartphones that are more interactive.

Social media networks through mobile phones can help women share experiences and learn from others. Community learning centers provide Internet computing facilities that allow villagers to interact with professionals online in 
order to broaden their worldviews. They are also important for socialization and can help to improve the self-confidence of participants.

Political will is urgently required at the national and international levels to drastically reduce the existing educational disparities in rural communities by enacting policies that are more inclusive and can increase quality in education. It has been found that rural populations are marginalized in many aspects socioeconomically, and are in dire need of long-term investment in skills development for sustainable livelihoods. It is therefore recommended that governments in developing countries work with international partners to sponsor long-term projects to generate modern skills for nonfarm income. Nevertheless, most of these governments lack capacity to sustain sponsored projects. Further, there is a dearth of evidence-based research on how ICT can reduce rural poverty. Hence, we recommend that more studies be undertaken to analyze and document ICTbased learning in rural communities.

The broader goals of education, training and skills development, should be premised on a holistic framework for poverty reduction, by identifying the relevant pathways out of rural poverty. It is important to nurture the learning capacity, innovation and productivity of rural people. With good coordination among members of rural communities and the school teachers, non-formal and informal learning programmes can be established to fit into their domestic chores and farm activities.

While normative goals such as the EFA, MDGs and SDGs are broad, committed global partnerships are vital to achieve them, as was in the case of increased school enrolments targeted in the MDGs. The Qingdao Declaration recognizes ICT as a central tool in realizing the SDGs. This provides developing countries with an opportunity to find solutions that can improve learning, especially in rural areas. In SSA, the structural transformation agenda aims to reduce rural-urban disparities and increase diversified sources of income, higher productivity, and improved living standards that are all important for rural transformation.

\section{References}

Ahmed, M. (2014). ERT challenges in the post-2015 era. Journal of Education and Research, 4(2), 72-86.

Alkire, S., Chatterjee, M., Conconi, A., Seth, S., \& Vaz, A. (2014). Poverty in rural and urban areas. Direct comparisons using the global MPI 2014. 
Retrieved from http://www.ophi.org.uk/wp-content/uploads/Poverty-inRural-and-Urban-Areas-Direct-Comparisons-using-the-Global-MPI-2014. pdf?f68d3a

Boto, I., Fotabong, E., Proctor, F., Lopes, I., \& Kebe, H. (2011). Major drivers for rural transformation in Africa. Brussels development briefing on rural transformation in Africa (Briefing No. 24). Retrieved from https:// brusselsbriefings.files.wordpress.com/2012/10/br-24-rural-transformation-inafrica-eng.pdf

Chapman, R., \& Slaymaker, T. (2002). ICTs and rural development: Review of literature, current interventions and opportunities for action (ODI Working Paper No. 192). London, England: Overseas Development Institute.

Clarke, S., Wylie, G., \& Zomer, H. (2013). ICT 4 the MDGs? A perspective on ICTs' role in addressing urban poverty in the context of the Millennium Development Goals. Information Technologies \& International Development, $9(4), 55-70$.

Coombs, P. H., \& Ahmed, M. (1974). Attacking rural poverty: How non-formal education can help. Baltimore, MD: Johns Hopkins University Press.

Enriquez, L., Grijpink, F., Manyika, J., Moodley, L., Sandoval, S., Sprague, K., \& Strandell-Jansson, M. (2014). Offline and falling behind: Barriers to Internet adoption. Retrieved from http://www.mckinsey.com/insights/high_ tech_telecoms_internet/offline_and_falling_behind_barriers_to_internet_ adoption.\#sthash.J9PFjWcO.dpuf

Food and Agriculture Organization. (2015). The state of food insecurity in the world 2015. Meeting the 2015 international hunger targets: Taking stock of uneven progress. Rome, Italy: Author.

Global System for Mobile Association's mWomen. (2013). Unlocking the potential: Women and mobile financial services in emerging markets. London, England: Author.

Haijun, Z., Weifeng, X., Jinghua, W., \& Rong, W. (Eds.). (2015). Approach of ICT in education for rural development: Good practices from developing countries. New Delhi, India: Sage.

Harris, R. W. (2004). Information and communication technologies for poverty alleviation.Kuala Lumpur, Malaysia: UNDP-APDIP. 
infoDev. (2010). ICT in non-formal education in India and South Asia. Retrieved from http://www.infodev.org/infodev-files/resource/InfodevDocuments_937. pdf

International Fund for Agricultural Development. (2010). Rural poverty report 2011. Rome, Italy: Author.

Isaacs, S. (2012). Turning on mobile learning in Africa and the Middle East: Illustrative initiatives and policy implications (UNESCO Working Paper Series on Mobile Learning 2012). Paris, France: UNESCO.

Kenny, C., \& Dykstra, S. (2013). The global partnership for development: A review of MDG 8 and proposals for the post-2015 development agenda (CGD Policy Paper 026). Washington, DC: Center for Global Development.

Khan, M. H. (2000). Rural poverty in developing countries: Issues and policies (WP/OO/78). Washington, DC: International Monetary Fund.

Khan, S. H., Hasan, M., \& Clement, C. K. (2012). Barriers to the introduction of ICT intoeducation in developing countries: The example of Bangladesh. International Journal of Instruction, 5(2), 61-80.

Li, W., Ahmed, M., Khan, K., \& Hongwei, M. (2016). Education and training for rural transformation. Skills, jobs, food and green future to combat poverty. New Delhi, India: Sage.

Madden, D. C. (2014). Inclusive education in rural Alberta, Canada: Utilizing ICT to support twenty-first century learning. In R. Huang, Kinshuk, \& J. K. Price (Eds.), ICT in education in global context: Emerging trends report 2013-2014 (pp. 19-30). Berlin, Germany: Springer-Verlag Berlin Heidelberg.

Mamba, M. S. N., \& Isabirye, N. (2015). A framework to guide development through ICTs in rural areas in South Africa. Information Technology for Development, 21(1), 135-150.

Minges, M., Kimura, K., Beschorner, N., Davies, R., \& Zhang, G. (2014).

Information and communications in the Chinese countryside: A study of three provinces. Washington, DC: World Bank.

Olinto, P., Beegle, K., Sobrado, C., \& Uematsu, H. (2013). The state of the poor: Where are the poor, where is extreme poverty harder to end, and what is the current profile of the world's poor? Economic Premise, 125, 1-8.

Pade-Khene, C., Mallinson, B., \& Sewry, D. (2011). Sustainable rural ICT project 
$124 \mid$ V. Chinapah\&J. O. Odero

management practice for developing countries: Investigating the Dwesa and RUMEP projects. Information Technology for Development, 17(3), 187-212.

Pokorska, A. (2012). ICT for inclusive learning: The way forward. Retrieved from https://repozytorium.umk.pl/bitstream/handle/item/1873/v10130-012-0011$\mathrm{x}$, Pokorska.pdf?sequence $=1$

Rabinowicz, S. G., \& Chinapah, V. (2014). Good practices in pursuit of sustainable rural transformation. Journal of Education and Research, 4(2), 7-23.

Scheil-Adlung, X. (Ed.). (2015). Global evidence on inequities in rural health protection: New data on rural deficits in health coverage for 174 countries. Geneva, Switzerland: International Labor Organization.

Schmitt, C. (2015). Why a mobile-technology revolution needs teachers. Retrieved from http://www.dw.com/en/lifelinks-education-mobile-africa/a-18358008

Sharma, T. N. (2014). Education for rural transformation: The role of community learning centers in Nepal. Journal of Education and Research, 4(2), 87-101.

Shimiles, A. (2015). Poverty: Shifting fortunes and new perspectives. In C. Monga, \& J. Y. Lin (Eds.), The Oxford handbook of Africa and economics: Context and concepts (Vol. 1, pp. 175-191). London, England: Oxford University Press.

Trucano, M. (2016). Mobile Internet buses, vans and classrooms to support teachers \& learners in remote communities. Retrieved from http://blogs. worldbank.org/edutech/mobile-internet-buses-vans-and-classrooms

UNESCO Institute for Statistics. (2015). A growing number of children and adolescents are out of school as aid fails to meet the mark (Policy Paper 22/ Fact Sheet 31). Paris, France: Author.

UNESCO International Research and Training Centre for Rural Education. (2001). Education for rural transformation: Towards a policy framework. Baoding, China: Author.

UNESCO International Research and Training Centre for Rural Education. (2012). Education and training for rural transformation: Skills, jobs, food and green future to combat poverty. Beijing, China: Author.

United Nations. (2014). Millennium development goals report 2014. New York, NY: Author. 
United Nations. (2015). Millennium development goals report 2015. New York, NY: Author.

United Nations Economic and Social Commission for Asia and the Pacific. (2010). Regional progress and strategies towards building the information society in Asia and the Pacific. Bangkok, Thailand: Author.

United Nations Educational, Scientific and Cultural Organization. (2005).

Guidelinesfor inclusion: Ensuring access to education for all. Paris, France: Author.

United Nations Educational, Scientific and Cultural Organization. (2010). Education for all global monitoring report 2010: Reaching the marginalized. Paris, France: Author.

United Nations Educational, Scientific and Cultural Organization. (2015a). The United Nations world water development report 2015: Water for a sustainable world. Paris, France: Author.

United Nations Educational, Scientific and Cultural Organization. (2015b). World education forum 2015 19-22 May 2015, Incheon, Republic of Korea. Retrieved from http://en.unesco.org/world-education-forum-2015/5-keythemes/quality-education

World Bank. (2016). World development report 2016: Digital dividends. Washington, DC: Author.

Yasunaga, M. (2014). Non-formal education as a means to meet learning needs of out-of-school children and adolescents (Background paper for "Fixing the broken promise of education for all: Findings from the global initiative on out-of-school children"). Montreal, Canada: UNESCO Institute for Statistics. 